\title{
Knowledge of asthma guidelines: results of a UK General Practice Airways Group (GPIAG) web-based 'Test your Knowledge' quiz
}

\author{
*Hilary Pinnocka, Steve Holmes ${ }^{b}$, Mark L Levya, Ruth McArthurc, lain R Small ${ }^{d}$ \\ a Senior Clinical Research Fellow, Allergy and Respiratory Research Group, Centre of Population Health Sciences: GP Section, University of \\ Edinburgh, Scotland, UK \\ ${ }^{\mathrm{b}}$ GPIAG Education Lead; Associate Dean GP Education, Severn Deanery, South West Strategic Health Authority, UK \\ ' National Training Co-ordinator (Scotland), Education for Health, UK \\ ${ }^{\mathrm{d}}$ Honorary Lecturer, Centre for Academic Primary Care, University of Aberdeen, Scotland, UK
}

Received 22nd March 2009; resubmitted 15th M ay 2009; revised version received 10th July 2009; accepted 12th July 2009; online 13th October 2009

\section{Summary}

A web-based questionnaire, comprising 11 multiple choice questions, tested the knowledge of visitors to the General Practice Airways Group (GPIAG) online summary of the British Asthma guideline. On average, the 413 respondents answered less than half the questions correctly. GP scores were significantly lower than practice nurses. Improving clinicians' knowledge of asthma is a prerequisite for improving management.

(C) 2010 Primary Care Respiratory Society UK. All rights reserved.

H Pinnock et al. Prim Care Resp J 2010; 19(2): 180-184

doi:10.4104/pcrj.2009.00052

Keyw ords asthma, BTS/SIGN guideline, questionnaire, web-based, knowledge, clinicians, GPIAG

\section{Introduction}

The British Thoracic Society and Scottish Collegiate Guideline Network (BTS/SIGN) guideline for the management of asthma has been updated regularly since its first publication in 2003. Its declared aim is to '[continue] to serve as a basis for high quality management of both acute and chronic asthma and a stimulus for research into areas of management for which there is little evidence'.' The 2008 update was published in Thorax and was available for download from both the BTS and SIGN web-sites.

Each update has been widely disseminated, with webbased resources proving popular. ${ }^{2}$ The UK General Practice Airways Group (GPIAG) has supported the dissemination of each update by publication of supplements to the Primary Care Respiratory Journa ${ }^{\beta}$ and the production of Opinion sheets (available from www.gpiag.org). Summary documents distilling the key points of the updated BTS/SIGN guideline for busy practitioners were produced by the GPIAG and made available on the GPIAG web-site in September 2008. This offered an opportunity to test the knowledge of visitors to the summary using a web-based questionnaire.

\section{Methods}

As part of the process of writing the BTS/SIGN summary, a web-questionnaire was designed by two members of the multi-disciplinary GPIAG education sub-committee (IS and RM). Eleven questions were devised, each reflecting a key point from one of the chapters of the BTS/SIGN guideline. The questions were discussed within the sub-committee before being piloted by GPIAG and non-GPIAG colleagues from a range of disciplinary backgrounds. After modification in the light of feedback, the final questionnaire was placed as the first page of the BTS/SIGN summary in an open-access area of the GPIAG web-site. Visitors to the site were invited to

\footnotetext{
* Corresponding author: Dr Hilary Pinnock, Allergy and Respiratory Research Group, Centre of Population Health Sciences: GP Section, University of Edinburgh, 20 West Richmond Street, Edinburgh, Scotland, EH8 9DX.

Tel: +44 (0)131 6508102 Fax: +44 (0)131 6509119 E-mail: hilary.pinnock@ed.ac.uk
} 
complete the questions before reading the summary document (in which the answers to most of the questions were available). Respondents were asked their professional group (GP, primary care nurse, secondary care nurse/respiratory nurse specialist, or a free text box for 'other') and whether or not they were members of the GPIAG. Most of the 11 multiple choice questions involved a choice of one out of the selection offered, but two questions (Q5 and Q11) required multiple choices to be made. The number of correct answers for each question was indicated. Responses were scored as correct or incorrect.

Categorical and continuous data were analysed according to type and distribution using SPSS version 16. In addition to descriptive statistics, responses between groups were compared using Chi-squared or independent sample t-tests.

\section{Results}

There were 3,560 hits recorded on the BTS/SIGN summary section of the GPIAG web-site. The questionnaire was completed by 413 people (11\% of the visitors), comprising 96 $(23.2 \%)$ general practitioners (GPs), $237(57.4 \%)$ primary care nurses (PCNs), 38 (9.2\%) secondary care nurses (SCNs), and $42(10.2 \%)$ other healthcare professionals - pharmacists (7), consultants (2), pharmaceutical company staff (2), media/writers (2), GP registrars (3), students (3), other nursing specialities (4), and a commissioner (1).

From a possible score of 11 , the average score was 5.2 (SD 2.56), with 24 of the respondents answering all the questions correctly and three scoring no correct answers (see Figure 1). On average GPs scored significantly less than primary care nurses, though scores for both groups ranged from 0 to 11 (mean score $\mathrm{GPs}=4.6$ vs $\mathrm{PCNs}=5.5$; mean difference -0.97 $(95 \% \mathrm{Cl}-1.6$ to -0.36$) \mathrm{p}=0.002)$. There was no difference between the scores of primary and secondary care nurses, or between GPIAG and non-GPIAG members (see Table 1).

Figure 1. Distribution of scores (all respondents).

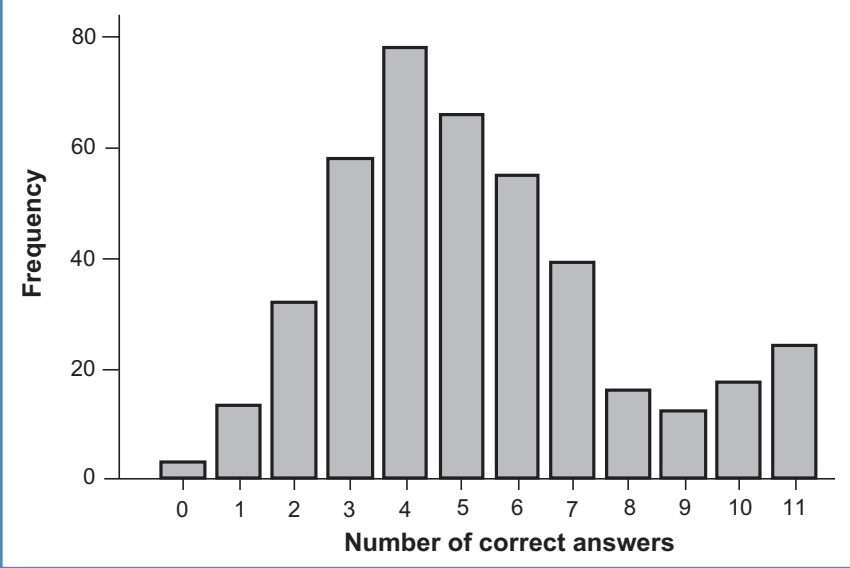

PRIMARY CARE RESPIRATORY JOURNAL www.thepcrj.org

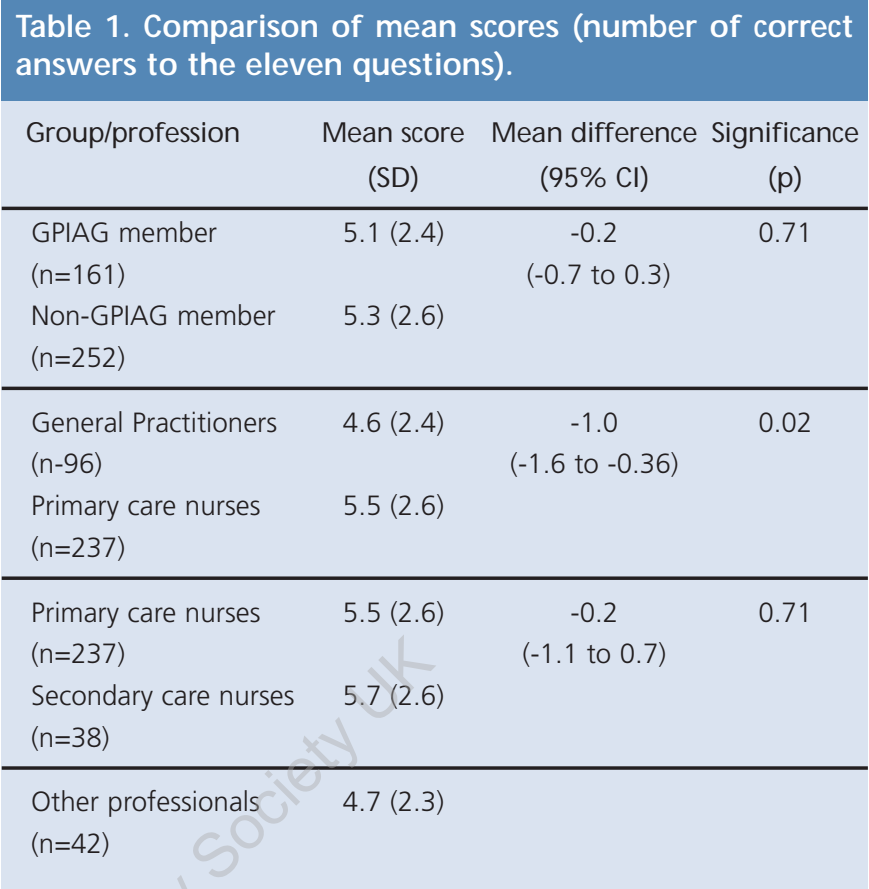

The proportion of respondents giving correct answers to individual questions is given in Table 2. There were differences between the professional groups, some of which were statistically significant. There was no significant difference between the responses of GPIAG members and non-GPIAG members except for question 11 - in which both groups returned very low scores (data not included).

\section{Discussion}

On average, the respondents to our web-survey answered less than half the questions correctly, suggesting that despite two decades of asthma guideline publication ${ }^{1,4}$ and considerable time and resources devoted to dissemination ${ }^{2,3,5}$ there is still much to do to ensure that every healthcare professional is familiar with guideline recommendations.

\section{Limitations}

Web-based questionnaires have significant limitations which should be considered when interpreting these data. The combination of a typically low response rate to webquestionnaires, and the type of respiratory-interested clinicians likely to have accessed the site, make it impossible to generalise our findings to the wider clinical community. However, it is likely that knowledge amongst professionals with less interest in asthma would be even less than that recorded in our survey.

Visitors to the web-site were invited to complete the questionnaire before working through the summary pages which provided all the required information. Although the questionnaire was the first page of the summary guideline section of the web-site, it was possible to return to it, and 
H Pinnock et al.

\section{Table 2. Proportion of correct responses to individual questions, and comparison between professional groups.}

Question (correct responses are indicated in bold)

Q1. In which group of children should clinicians take the following approach? Watchful waiting with review:

a. Those with a high probability of asthma

b. Those with a low probability of asthma

c. Those with an intermediate probability of asthma

Q2. To help make a diagnosis of asthma in adults, which one of the following is considered to be a significant improvement in FEV ${ }_{1}$ after a reversibility test in the UK?
a. $200 \mathrm{ml}$
b. $400 \mathrm{ml}$
c. $10 \%$

Q3. Non-pharmacological management: Studies of individual aeroallergen avoidance strategies show which one of the following statements to be true?

a. Limited or of no benefit

b. Cost effective

c. Removal of the domestic pet leads to improved asthma outcomes

Q4. In an adult using short-acting beta-2-agonists 8-10 times per week over the past 3 months, who is already taking $400 \mathrm{mcg}$ per day of BDP, which of the following is recommended?

a. The addition of a long- acting beta-2-agonist (LABA)

b. Stepping-up (increasing) the dose of inhaled corticosteroids (ICS) to $800 \mathrm{mcg}$ per day

c. A short course of oral steroids to regain control

d. An asthma review including inhaler technique and concordance, then add LABA if these are satisfactory

e. Switch to a different ICS

Q5. What is the maximum dose of inhaled steroid in a 7-year old poorly controlled asthmatic child, before adding additional therapy or referring? The child has perfect inhaler technique. (more than one answer possible)

a. Clenil ${ }^{\oplus}$ Modulite $^{\circledast} 100 \mathrm{mcg} 2$ puffs bd

b. CFC BDP $100 \mathrm{mcg}$ bd

c. Fluticasone $100 \mathrm{mcg}$ bd

d. Budesonide $200 \mathrm{mcg}$ bd

e. Qvar $50 \mathrm{mcg}$ bd

Q6. Assessment of acute asthma: According to the guidelines, when assessing an adult, which one of the following is a cardinal sign of life threatening asthma?

a. Pulse rate 120 beats per min

b. Respiratory Rate 32 per min

c. Pulse oximetry $\left(\mathrm{SpO}_{2}\right) \mathbf{9 1 \%}$

d. Widespread wheeze in the chest

e. inability to talk in sentences

Q7. Treatment of acute asthma: Identify which statement is true from those listed.

According to the guidelines, patients who have been treated for acute severe asthma:

a. Should have their bronchodilators given via nebuliser

b. Should be admitted until their PEF returns to $>80 \%$

c. May be treated in a pre-hospital environment using IV magnesium

d. Should be given a personal asthma action plan

e. Should be reviewed in practice within 48hrs - their GP having been notified

Q8. Asthma in Pregnancy: Which one group of the following drug types should not be initiated in pregnancy?

a. Inhaled steroids

b. Oral steroids

c. Theophyllines

d. Leukotriene receptor antagonists

Q9. Organisation and delivery of care: Which one of the following recommendations

for routine delivery of asthma care in general practice has Grade A evidence?

a. Clinical review should be structured and utilise a standard recording system

b. General practices should maintain an up-to-date register of people with asthma

c. People with asthma should be reviewed regularly by a doctor or a nurse with appropriate training in asthma management

d. Carrying out routine reviews by telephone for people with asthma may be as effective as face-to-face consultations

Q10. Patient education and self management: The guidelines recommend that a

personalised asthma action plan should have which one of the following

characteristics?

a. Be symptoms only based

b. Have 4 or more action points

c. Be based on peak flow only

d. Advise patients to go straight to the oral steroid step if they are already taking $>400 \mathrm{mcg}$ of inhaled steroid normally

Q11. Occupational asthma: A 43 year old welder develops symptoms suggestive of

asthma. What would you advise? (more than one answer possible)

a. He should come off work and avoid exposure to potential allergens

b. He should do PEF measurements twice daily to confirm diagnosis

c. He should stop smoking

d. He should be told to seek compensation to which they will be entitled

e. He should be referred for specialist assessment

Key: $\mathrm{GP}=$ general practitioner; $\mathrm{PCN}=$ primary care nurse; $\mathrm{SCN}=$ secondary care nurse; other = other healthcare professional

Note: Significance refers to the comparison between the four groups using a $\mathrm{Chi}^{2}$ test of significance

$\begin{array}{ccccc}\text { All } & \text { GPS } & \text { PCN } & \text { SCN } & \text { Others Si } \\ & & & & \\ & & & & \\ 190 / 411 & 31 / 96 & 113 / 236 & 24 / 37 & 22 / 42 \\ (46.2 \%) & (32.5 \%) & (47.9 \%) & (64.9 \%) & (52.4 \%) \\ & & & & \\ & & & & \\ 262 / 405 & 48 / 94 & 170 / 232 & 25 / 37 & 19 / 42 \\ (64.7 \%) & (51.1 \%) & (73.3 \%) & (67.6 \%) & (45.2 \%) \\ & & & & \\ & & & & \\ 304 / 408 & 61 / 95 & 185 / 234 & 31 / 37 & 27 / 42 \\ (74.5 \%) & (64.3 \%) & (79.1 \%) & (83.8 \%) & (64.3 \%)\end{array}$

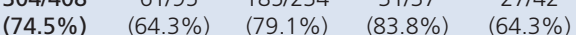

$\begin{array}{lllll}332 / 410 & 76 / 95 & 197 / 235 & 30 / 38 & 28 / 42\end{array}$

$\begin{array}{llll}(81.0 \%) & (80.0 \%) \quad(83.8 \%) & (78.9 \%) \quad(69.0 \%)\end{array}$

0.15

$144 / 395$

$(36.5 \%)$

$25 / 92$

$100 / 227$

$9 / 35$

(25.7\%)

$10 / 41$

(24.4\%)

$<0.01$

95/230

$13 / 38$

$14 / 42$

(38.8\%) (36.8\%) (41.3\%) (34.2\%)

01 
some of the respondents may have read the summary pages before completing the questions. In addition, the full BTS/SIGN guideline was freely available, and a range of summaries and articles had appeared in journals and magazines. We do not know which other resources respondents had accessed, or whether they referred to them when responding to the questions.

The technique of answering multiple choice questions may have impacted on the results. The decision to omit a question, or guess the answer, will affect the results - though analysing the data assuming that all the omitted answers were incorrect does not significantly alter the outcomes.

\section{Interpretation of findings in relation to previously published work}

The better performance of primary and secondary care specialist nurses compared to GPs in their answers to some questions (diagnosis, allergens, inhaler devices and organisation of care) may be interpreted in a number of ways. It may highlight the challenge to generalists of maintaining a knowledge base in the very broad range of conditions dealt with in general practice; this reinforces the guideline recommendation that routine reviews should be provided by professionals with 'appropriate training'. ${ }^{1}$ To some extent, performance reflected the distribution of roles within many UK practices, where asthma nurses check and select inhaler devices (Q5) and organise routine care (Q9), whilst GPs provide unscheduled appointments for people with acute symptoms (Q6 and Q7). ${ }^{6}$ Nurses are increasingly involved with making a diagnosis (Q1 and Q2), especially if lung function tests are involved (Q2). ${ }^{6}$ Within UK practice, two-thirds of practice nurses have an 'advanced role' in asthma care, defined as 'autonomously confirming the diagnosis and providing routine follow-up care'. ${ }^{6}$.

The question with the lowest score was Q11 which asked about occupational asthma. In fact, 304 (74\%) of respondents recognised that the patient should be referred to a specialist and correctly selected that option. However, to score a correct answer the respondent also had to select 'advise smoking cessation', which was achieved by only 60 $(14.5 \%)$. Although it is a recommendation in the guideline, many respondents may have considered smoking cessation as generic health promotion advice rather than it being specifically related to occupational asthma.

The mean score of $39 \%$ (with no significant difference between the professional groups) for the question about signs of life-threatening asthma reflects previously-noted concerns about the assessment of acute asthma, ${ }^{7}$ and raises the issue of how to facilitate implementation of guideline recommendations. It is recognised that simple dissemination of information is insufficient, and more complex initiatives are required to effect change. ${ }^{8}$ The range of backgrounds of our respondents suggests a need for accessible forms of information extending across traditional professional boundaries.

Implementing guidelines remains a crucial challenge. ${ }^{9}$ There are many recognised barriers, including lack of knowledge or misconceptions about recommendations, as well as practical difficulties inherent in a busy general practice. ${ }^{10-12}$ Compliance with key guideline recommendations has been linked with effective delegation to specialist asthma nurses within a practice organisation enabling good communication and engendering mutual trust and respect. ${ }^{13}$ This resonates with our findings that both primary and secondary care nurses can provide important specialist knowledge, particularly in aspects of routine management.

\section{Conclusion}

There is still an urgent need to disseminate the key messages from the BTS/SIGN asthma guideline. Although the Quality and Outcomes Framework has promoted the provision of routine asthma reviews, ${ }^{14}$ this does not ensure compliance with all guideline recommendations and too many patients still have poorly controlled asthma. ${ }^{15}$ Compliance with guidelines is multifactorial, ${ }^{12,13}$ but improving healthcare professionals' knowledge of asthma is an important prerequisite.

\section{Funding}

The GPIAG Asthma guideline summary project was funded by an educational grant from GlaxoSmithKline (GSK). HP is supported by a Primary Care Research Career Award from the Chief Scientist's Office of the Scottish Government.

\section{Conflict of interest declaration}

HP has received honoraria, educational and travel grants from GlaxoSmithKline, AstraZeneca and Teva.

SH has accepted sponsorship for attending conferences from, has accepted lecture fees from, or has been on advisory boards or provided consultancy for, the following companies; Altana Pharma, AZ, BI, GSK, MEDA Pharmaceuticals, MSD, Chiesi, Novartis and Schering Plough.

MLL has accepted sponsorship from GSK, AstraZeneca (AZ), Chiesi, Merck Sharpe and Dohme (MSD), Merck, Altana Pharma, Novartis, Meda Pharmaceuticals, 3M Pharmaceuticals and Schering Plough for attending conferences. He has accepted lecture fees from Boehringer Ingelheim, GSK, AZ and Alk-Abello. He has been on advisory boards or provided consultancy for Schering Plough, MSD, Cheisi, Altana Pharma, Ranbaxy, AZ, 3M Pharmaceuticals and Novartis. He has received research grants from GSK, AZ and Boehringer Ingelheim. He is a member of ADMIT (The Aerosol Drug Management Improvement Team) which is funded through an unrestricted educational grant by MEDA Pharmaceuticals. MLL is the Editor-in-Chief of the Primary Care Respiratory Journal, but was not involved in the editorial review of, nor the decision to publish, this article.

RM CA has travel grants, sponsorship to attend meetings, honorania for speaker meetings and advisory boards from AZ, GSK, Nycomed, Chiesi and Boeringher in the past year.

IS has received honoraria and travel grants to attend conferences from GSK, AZ, Chiesi, Boehringer Ingelheim, TEVA and Nycomed

\section{Contributorship}

IS and RM developed the original questionnaire in consultation with members of the GPIAG education sub-committee chaired by SH. MLL assisted with on-line 
H Pinnock et al.

publication, testing and editing of the final questionnaire. HP wrote the report. All authors commented on the report and approved the final version of the manuscript.

\section{Acknowledgements}

We acknowledge the contribution of Anne Smith, Chief Executive Officer of the GPIAG, Tricia Bryant, GPIAG secretariat, and members of the Education subcommittee (Raj Ramachandram, Stephanie Wolfe, Stephanie Reilly, Jane Scullion and Andrew Brown) who contributed to the project. Lynn Danzig designed the web-site.

\section{References}

1. British Thoracic Society-Scottish Intercollegiate Guideline Network. British Guideline on the Management of Asthma. Thorax 2008;63(Suppl 4):1-121. http://www.brit-thoracic.org.uk and http://www.sign.ac.uk

2. Dennis SM, Edwards S, Partridge MR, Pinnock HJ, Qureshi S. The dissemination of the British Guideline on the Management of Asthma 2003. Respir Med 2004;98:832-7. http://dx.doi.org/10.1016/j.rmed.2004.02.018

3. Levy ML, Thomas M, Small IR, Pearce L, Pinnock H, Stephenson P. Summary of the 2008 BTS/SIGN British Guideline on the Management of Asthma. Prim Care Resp J 2009;18(Suppl1):S1-S16. http://dx.doi.org/10.3132/pcrj.2008.00067

4. British Thoracic Society. Guidelines for the management of Asthma: I: chronic persistent asthma. BMJ 1990:301:651-3. http://dx.doi.org/ 10.1136/bmj.301.6753.651

5. Partridge MR, Harrison BDW, Rudolph M, Bellamy D, Silverman M. The British Asthma Guidelines - their production, dissemination and implementation. Respir Med 1998;92:1046-52. http://dx.doi.org/10.1016/S09546111(98)90353-5

6. Upton J, Madoc-Sutton H, Sheikh A, Frank TL, Walker S, Fletcher M. National survey on the roles and training of primary care respiratory nurses in the UK in 2006: are we making progress? Prim Care Resp J 2007;16:284-90. http://dx.doi.org/10.3132/pcrj.2007.00068

7. Pinnock $\mathrm{H}$, Johnson $A$, Young $P, M$ artin $N$. Are doctors still failing to assess and treat asthma attacks? An audit of the management of acute attacks in a Health District. Respir Med 1999;93:397-401.

8. Foster J, Hoskins G, Smith B, Lee AJ, Price D, Pinnock H. Practice development plans to improve the primary care management of acute asthma: randomised controlled trial. BMC Family Practice 2007;8:23. http://dx.doi.org/ 10.1186/1471-2296-8-23

9. Levy ML. Guideline-defined asthma control: a challenge for primary care. Eur Respir J 2008;31:229-31. http://erj.ersjournals.com/cgi/content/full/31/2/229 http://dx.doi.org/10.1183/09031936.00157507

10. Wiener-Ogilvie $S$, Pinnock $H$, Huby $G$, Sheikh A, Partridge $M R$, Gillies J, Do practices comply with key recommendations of the British Asthma Guideline, and if not, why not? Prim Care Resp J 2007;16:369-77. http://dx.doi.org/10.3132/pcrj.2007.00074

11. Barton C, Proudfoot J, Amoroso C, et al. Management of asthma in Australian general practice: care is still not in line with clinical practice guidelines. Prim Care Resp J 2009;18(2):100-05. http://dx.doi.org/10.3132/pcrj.2008.00059

12. Cabana M, Rand C, Powe N, et al. Why don't physicians follow practice guidelines: a framework for improvement. JAMA 1999,282:1458-65. http://dx.doi.org/10.1001/jama.282.15.1458

13. Wiener-Ogilvie S, Huby G, Pinnock H, Gillies J, Sheikh A. Practice organisational characteristics can impact on compliance with the BTS/SIGN asthma guideline: Qualitative comparative case study in primary care. BMC Family Practice 2008, 9:32. http://dx.doi.org/10.1186/1471-2296-9-32

14. NHS Confederation, British Medical Association New GMS Contract 2003: investing in general practice. London. March 2003. http://www.nhsemployers.org/SiteCollectionDocuments/gms_contract_cd_130 209.pdf

15. Haughney J, Barnes G, Partridge M, Cleland J. The Living \& Breathing study: a study of patients' views of asthma and its treatment. Prim Care Resp J 2004; 13:28-35. http://dx.doi.org/10.1016/j.pcrj.2003.11.007

\section{Available online at http://ww w.thepcrj.org}

